\title{
Efficacy of combination therapy with telmisartan plus amlodipine in patients with poorly controlled hypertension
}

\author{
Hisatoshi Bekki, ${ }^{1}$ Kiichiro Yamamoto, ${ }^{1}$ Masayoshi Sone, ${ }^{1}$ Tomoki Homma, Masashi Nakata, ${ }^{1}$ Masatoshi Nohara, ${ }^{1}$ Kei Fukami, ${ }^{1,2}$ \\ Seiya Okuda, ${ }^{1,2}$ and Sho-ichi Yamagishi', \\ 'ABC Trial Group; Kurume, Japan; ${ }^{2}$ Department of Medicine; Division of Nephrology; ${ }^{3}$ Department of Pathophysiology and Therapeutics of Diabetic Vascular Complications; \\ Kurume University School of Medicine; Kurume, Japan
}

Key words: BP control, combination therapy, telmisartan, central BP, amlodipine

\begin{abstract}
There is accumulating evidence that blood pressure (BP) control significantly reduces the risk of future cardiovascular events in patients with essential hypertension. However, strict BP control is often difficult to maintain, and half of hypertensive patients fail to attain BP goals on single-drug therapy. Therefore, current guidelines recommend combinations of drugs that have complimentary mode of actions for treatment of patients with moderate hypertension. In this study, we examined in hypertensive patients uncontrolled by the combination treatment with $5 \mathrm{mg}$ amlodipine plus $80 \mathrm{mg}$ valsartan or $8 \mathrm{mg}$ candesartan whether additional BP lowering could be achieved by switching to $5 \mathrm{mg}$ amlodipine plus $40 \mathrm{mg}$ telmisartan. Forty-seven patients with essential hypertension who failed to achieve a target BP level by the treatment of $5 \mathrm{mg}$ amlodipine plus $80 \mathrm{mg}$ valsartan or $8 \mathrm{mg}$ candesartan for at least 2 months were enrolled. Replacement of valsartan or candesartan by telmisartan showed a significant reduction in both mean clinic systolic and diastolic BP at 4, 8 and 12 weeks; BP level decreased from $143.7 / 82.3 \mathrm{mmHg}$ at baseline to $135.4 / 77.5 \mathrm{mmHg}$ at 12 weeks. Furthermore, in 8 patients of valsartan group, switching to telmisartan significantly reduced central BP by $11.8 \mathrm{mmHg}$. Our present study suggests that combination therapy with telmisartan plus amlodipine may be more beneficial than valsartan or candesartan plus amolodipine treatment for controlling brachial and central BP, which could lead to more favorable cardiovascular outcomes with this drug combinations.
\end{abstract}

\section{Introduction}

There is a growing body of evidence that blood pressure (BP) level is one of the major determinants of cardiovascular morbidity and mortality in individuals. ${ }^{1,2} \mathrm{~A}$ recent analysis by the Blood Pressure Lowering Treatment Trialists' Collaboration (BPLTTC) revealed that any commonly used BP-lowering regimen reduced the risk of total major cardiovascular events, and larger lowering in BP level produced larger reductions in the risk. ${ }^{3}$ These observations suggest that most of the differences among treatment regimens in their effects on cardiovascular outcomes could be explained by the differences in achieved BP level. However, it may also be true that some treatment regimen is superior or inferior to others with regard to the risk reduction of cardiovascular events. ${ }^{4-6}$ Indeed, in Avoiding Cardiovascular Events through Combination Therapy in Patients with Living with Systolic Hypertension (ACCOMPLISH) trial, combination of the inhibitor of renin-angiotensin system (RAS) with amlodipine, one of the most widely used dihydropyridine calcium channel blocker (CCB), demonstrated a significant risk reduction in cardiovascular events in patients with hypertension compared to the RAS inhibitor-hydrochlorothiazide combination. ${ }^{6}$

Angiotensin II (Ang II) is a physiologically active major substance of the RAS; it not only acts as a vasopressor by inducing vasoconstriction, but also elicits water and sodium absorption in the proximal renal tubule by stimulating secretion of aldosterone. ${ }^{5,7}$ Furthermore, Ang II exerts various biological effects in blood vessel, kidney and heart via the interaction with type 1 receptor., Therefore, inhibition of the RAS by angiotensin-converting enzyme inhibitors (ACEIs) and/or Ang II type 1 receptor blockers (ARBs) may be a therapeutic target for the organ protection in patients with hypertension. ${ }^{8}$

ARBs have less adverse reactions; they are unlikely to cause dry cough and angioedema associated with ACEIs. ${ }^{9}$ Since risk of cough from ACEIs is relatively high in East Asian compared with white patients, ${ }^{10} \mathrm{ARBs}$ are now a more popular RAS inhibitor in Japan. Although CCBs and ARBs are one of the recommended combinations in order to achieve target BP level, ${ }^{11}$ optimal combination regimen is not well established. Valsartan, candesartan and telmisartan are effective and well-tolerated ARBs, and their usual dosages 


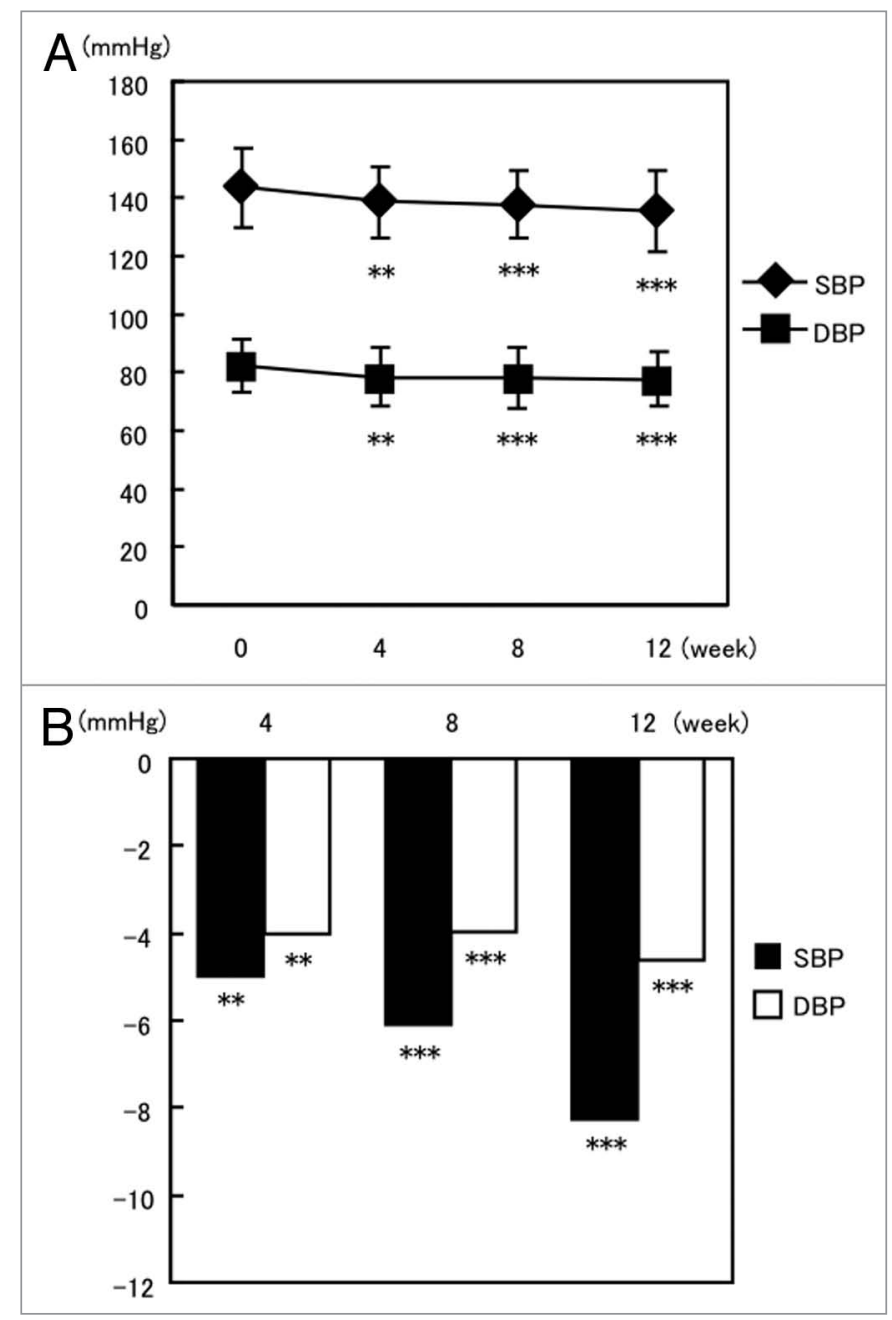

Figure 1. BP levels in whole patients. Replacement of valsartan or candesartan by telmisartan showed a significant reduction in both mean systolic blood pressure (SBP) and diastolic blood pressure (DBP) at 4,8 and 12 weeks. Forty-seven patients ( 36 males and 11 females) with poorly controlled hypertension were assigned to replace $80 \mathrm{mg}$ valsartan or $8 \mathrm{mg}$ candesartan with $40 \mathrm{mg}$ telmisartan. All patients were taking $5 \mathrm{mg}$ amlodipine. (A) SBP and DBP at baseline (0 week) and at 4 , 8 and 12 weeks after telmisartan treatment. (B) Mean changes in SBP and DBP from baseline. ${ }^{* *}$ and ${ }^{* *}, p<0.01$ and $p<0.001$ compared to the values of baseline, respectively.

are $80 \mathrm{mg}, 8 \mathrm{mg}$ and $40 \mathrm{mg}$ once daily, respectively in Japan. ${ }^{12}$ Therefore, we examined in hypertensive patients whose BP level was uncontrolled by combination treatment with $5 \mathrm{mg}$ amlodipine plus $80 \mathrm{mg}$ valsartan or $8 \mathrm{mg}$ candesartan for at least 2 months whether additional BP lowering could be achieved by switching to $5 \mathrm{mg}$ amolodipine plus $40 \mathrm{mg}$ telmisartan. We also investigated whether combination therapy with telmisartan and amlodipine was more effective in reducing central aortic pressures compared with valsartan or candesartan plus amlodipine treatment.

\section{Results}

Demographical data of the subjects are presented in Table 1. As shown in Figure 1, replacement of valsartan or candesartan by telmisartan in amlodipine-treated hypertensive patients showed a significant reduction in both mean clinic systolic BP (SBP) and diastolic BP (DBP) at 4, 8 and 12 weeks; BP level decreased from $143.7 / 82.3 \mathrm{mmHg}$ at baseline to $135.4 / 77.5 \mathrm{mmHg}$ at 12 weeks after the telmisartan treatment. When valsartan and candesartan group was separately analyzed, switching from valsartan to telmisartan had more beneficial BP-lowering effects (Figs. 2 and 3); replacement of valsartan by telmisartan reduced mean SBP and DBP by 7.1 and $6.5 \mathrm{mmHg}$ at 4 weeks, 6.9 and $5.0 \mathrm{mmHg}$ at 8 weeks, 10.5 and $7 . \mathrm{mmHg}$ at 12 weeks, respectively. Furthermore, although central BP (cBP) and augmentation index (AI) were evaluated in only 8 patients of valsartan group, switching to telmisartan significantly reduced cBP by $11.8 \mathrm{mmHg}$ (Table 2). There were no significant differences among low-density lipoprotein-cholesterol (LDL-C), triglycerides (TG), high-density lipoprotein-cholesterol (HDL-C), fasting plasma glucose (FPG), glycosyalted hemoglobin (HbAlc), insulin, homeostasis model assessment of insulin resistance (HOMA-IR) index, creatinine (Cr), estimated glomerular filtration rate (eGFR) values and AI before and after the treatment of telmisartan (Tables 1 and 2).

\section{Discussion}

Hypertension is one of the major risk factors of cardiovascular disease, and to control BP level appropriately is a therapeutic target for preventing future cardiovascular events in individuals. ${ }^{1,2,13,14}$ However, strict BP control is often difficult to maintain, and BP level is not adequately controlled in more than $50 \%$ of hypertensive patients on single-drug therapy. ${ }^{15}$ Therefore, current guidelines recommend combinations of drugs with different mode of actions for treatment of patients with moderate hypertension. ${ }^{11,16}$ There are several papers to show that combination therapy with ARBs and amlodipine, one of the most popular $\mathrm{CCBs}$ is effective for BP control compared with high-dose monotherapy, although what types of ARBs in combination with amlodipine are more effective for achieving appropriate BP control is not well established. ${ }^{17,18}$

In this study, we demonstrated for the first time that in hypertensive patients uncontrolled by the combination treatment with $5 \mathrm{mg}$ amlodipine plus $80 \mathrm{mg}$ valsartan or $8 \mathrm{mg}$ candesartan, additional BP lowering was achieved by switching to $5 \mathrm{mg}$ amlodipine plus $40 \mathrm{mg}$ telmisartan. BP level was significantly decreased at 4 weeks after the telmisartan treatment and remained low during the study periods. Furthermore, replacement of valsartan by telmisartan was found to significantly reduce $\mathrm{cBP}$ in our subjects as well. There are accumulating evidence that $\mathrm{cBP}$ is closely associated with coronary risk factors and future cardiovascular events in patients with hypertension. ${ }^{19,20}$ Therefore, our present findings suggest that combination therapy with telmisartan plus amlodipine may be more beneficial than valsartan or candesartan plus amolodipine treatment for controlling brachial and cBP, which could lead to more favorable cardiovascular outcomes with this drug combinations.

We have previously found that telmisartan has the strongest binding affinity to Ang II type 1 receptor among various 
ARBs, including valsartan and candesartan. ${ }^{21}$ Further, telmisartan has a half-life of about 24 hours, which is longer than that of valsartan and candesartan (about 9 hours). ${ }^{7}$ Among the ARBs, telmisartan is the most lipophilic compound as well. ${ }^{22}$ Therefore, due to its strongest Ang II type 1 receptor antagonistic ability, longest halflife and lipophilicity, switching to telmisartan may have long-lasting BP lowering effects in our uncontrolled hypertensive patients who were treated with $5 \mathrm{mg}$ amlodipine plus $80 \mathrm{mg}$ valsartan or $8 \mathrm{mg}$ candesartan. In support of this, it has been reported in clinical studies that telmisartan is significantly superior to valsartan in antihypertensive effect during the daytime and early morning, ${ }^{23,24}$ and that it produces a sustained antihypertensive effect equal to or greater than amlodipine, a long-acting CCB. ${ }^{25}$ Further, metaanalysis revealed that BP lowering effect of $40 \mathrm{mg}$ telmisartan was stronger than that of $80 \mathrm{mg}$ valsartan or $8 \mathrm{mg}$ candesartan. ${ }^{26}$

\section{Research Design and Methods}

Subjects. This was a prospective, open-label, 12-week study. Forty-nine patients with essential hypertension not achieving a target clinic or home BP level were recruited from multiple centers in Japan. ${ }^{27}$ All patients were taking $5 \mathrm{mg}$ amlodipine plus $80 \mathrm{mg}$ valsartan or $8 \mathrm{mg}$ candesartan for at least 2 months. A screening period of up to 2-4 weeks was used to assess eligibility and to eliminate prior medications. Finally eligible 47 patients (36 males and 11 females, mean age; $64.8 \pm 12.1$ years old) were assigned to replace valsartan or candesartan with $40 \mathrm{mg}$ telmisartan. During the study period, subjects were instructed not to change their lifestyles and to continue taking the same dose of any concomitant drugs. We excluded any patients with secondary hypertension, chronic liver disease, severe chronic heart failure, and those who had recent ( $<6$ months) acute coronary syndromes, stroke and any acute infections. Patients whose age was younger than 20 years old, whose BP level was $\geq 180 / 110$ $\mathrm{mmHg}$, or whose serum $\mathrm{Cr}$ level was $\geq 1.5 \mathrm{mg} / \mathrm{dL}$ were also excluded. At baseline, 4, 8 and 12 weeks after the replacement, clinic BP level was monitored. Anthropometric and metabolic variables and serum chemistries were also measured at baseline and at 12 weeks after telmisartan treatment as described previously. ${ }^{28}$ Only one male patient on switching from valsartan to telmisartan was dropped out at 8 weeks because of his personal reason. Informed consent was obtained from all the subjects, and the study protocol was approved by the Institutional Ethics Committee of Kurume University School of Medicine.
Table 1. Clinical variables at baseline and at 12 weeks after telmisartan treatment

\begin{tabular}{|cccc}
\hline Clinical variables & Baseline & At 12 weeks & p-value \\
\hline BMI $\left(\mathrm{kg} / \mathrm{m}^{2}\right)$ & $24.8 \pm 3.5$ & $24.7 \pm 3.6$ & 0.37 \\
\hline Heart rate (beats/minute) & $68.4 \pm 11.9$ & $68.0 \pm 11.2$ & 0.75 \\
SBP $(\mathrm{mmHg})$ & $143.7 \pm 13.6$ & $135.4 \pm 14.0$ & $\mathrm{p}<0.001$ \\
DBP $(\mathrm{mmHg})$ & $82.3 \pm 9.4$ & $77.5 \pm 9.4$ & $\mathrm{p}<0.001$ \\
\hline LDL-cholesterol $(\mathrm{mg} / \mathrm{dL})$ & $112.6 \pm 29.4$ & $111.4 \pm 27.0$ & 0.46 \\
\hline Triglycerides $(\mathrm{mg} / \mathrm{dL})$ & $159.9 \pm 167.9$ & $132.0 \pm 74.4$ & 0.23 \\
\hline HDL-cholesterol $(\mathrm{mg} / \mathrm{dL})$ & $55.1 \pm 12.3$ & $54.8 \pm 11.2$ & 0.93 \\
\hline Fasting plasma glucose $(\mathrm{mg} / \mathrm{dL})$ & $111.5 \pm 36.5$ & $111.7 \pm 42.7$ & 0.95 \\
\hline HbA1c $(\%)$ & $6.0 \pm 1.1$ & $6.0 \pm 0.8$ & 0.63 \\
\hline Fasting insulin $(\mu \mathrm{U} / \mathrm{mL})$ & $9.1 \pm 11.8$ & $8.5 \pm 10.4$ & 0.72 \\
\hline HOMA-IR & $2.4 \pm 3.0$ & $2.3 \pm 3.3$ & 0.85 \\
\hline Creatinine $(\mathrm{mg} / \mathrm{dL})$ & $0.7 \pm 0.2$ & $0.7 \pm 0.2$ & 0.32 \\
\hline eGFR (ml/min/1.73m $)$ & $79.1 \pm 17.2$ & $79.6 \pm 17.1$ & 0.46 \\
\hline Diabetes mellitus $(\mathrm{N})$ & 12 & 12 & - \\
\hline Dyslipidemia $(\mathrm{N})$ & 27 & 27 & - \\
\hline Chronic kidney disease $(\mathrm{N})$ & 3 & 3 & - \\
\hline Cardiovascular disease $(\mathrm{N})$ & 4 & 4 & - \\
\hline
\end{tabular}

Replacement of valsartan or candesartan by telmisartan showed a significant reduction in both mean systolic blood pressure (SBP) and diastolic blood pressure (DBP) at 12 weeks. BMI; body mass index, LDL-cholesterol; low-density lipoprotein-cholesterol, HDL-cholesterol; high-density lipoprotein-cholesterol, HbA1c; glycosyalted hemoglobin, HOMA-IR; homeostasis model assessment of insulin resistance, eGFR; estimated glomerular filtration rate, $\mathrm{N}$; number.

Table 2. Central BP at baseline and at 12 weeks after telmisartan treatment

\begin{tabular}{|cccc}
\hline Clinical variables & Baseline & At 12 weeks & p-value \\
Patients $(\mathrm{N})$ & 8 & 8 & - \\
\hline Age (years old) & $55.1 \pm 8.7$ & - & - \\
Male/female (N) & $7 / 1$ & $7 / 1$ & - \\
BMl (kg/m²) & $24.7 \pm 3.6$ & $24.9 \pm 3.7$ & 0.13 \\
Heart rate (beats/minutes) & $71.3 \pm 2.1$ & $74.3 \pm 7.1$ & 0.28 \\
SBP2 (mmHg) & $129.3 \pm 7.7$ & $118.4 \pm 9.4$ & $\mathrm{p}<0.05$ \\
Central BP (mmHg) & $144.9 \pm 8.2$ & $133.1 \pm 10.1$ & $\mathrm{p}<0.05$ \\
Al (\%) & $71.8 \pm 16.5$ & $72.9 \pm 20.0$ & 0.82 \\
\hline
\end{tabular}

Replacement of valsartan by telmisartan showed a significant reduction in central blood pressure (central BP) at 12 weeks. BMI; body mass index, SBP2; late systolic peak of blood pressure, BP; blood pressure, Al; augmentation index, N; number.

Study design. The medical history was ascertained by a questionnaire. Height and weight were measured, and body mass index (BMI: kilograms per meter squared) was calculated as an index of the presence or absence of obesity. Clinic BP was measured in the sitting position using an upright standard sphygmomanometer after at least $5 \mathrm{~min}$ of rest in the morning before taking anti-hypertensive agents. Three measurements were taken $1 \mathrm{~min}$ apart, and mean of the last two recordings was used as BP level. Using applanation tonometry (HEM-9000AI (Omron Healthcare, Kyoto, Japan), cBP was deduced noninvasively from the amplitude of the late systolic peak (SBP2) of the radial artery pulse waveform as 


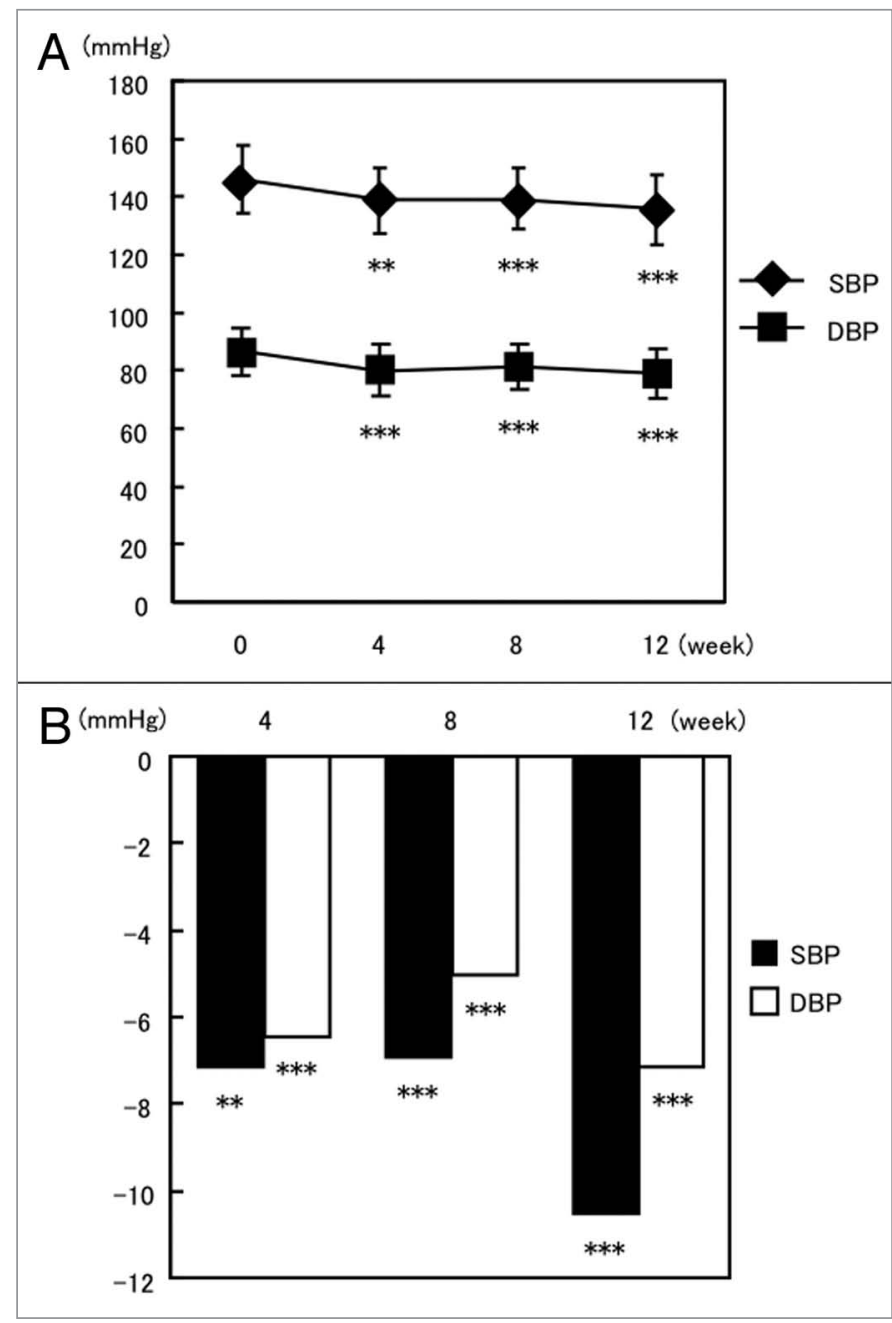

Figure 2. BP levels in patients on switching from valsartan to telmisartan. Replacement of valsartan by telmisartan showed a significant reduction in both mean systolic blood pressure (SBP) and diastolic blood pressure (DBP) at 4, 8 and 12 weeks. Twenty-two patients (17 males and 5 females) with poorly controlled hypertension were assigned to replace $80 \mathrm{mg}$ valsartan by $40 \mathrm{mg}$ telmisartan. All patients were taking $5 \mathrm{mg}$ amlodipine. (A) SBP and DBP at baseline (0 week) and at 4,8 and 12 weeks after telmisartan treatment. (B) Mean changes in SBP and DBP from baseline. ${ }^{* *}$ and ${ }^{* * *}, p<0.01$ and $p<0.001$ compared to the values of baseline, respectively.

described elsewhere. ${ }^{29}$ The AI was calculated as the ratio of the amplitude of SBP2 to the amplitude of the early systolic peak.

Blood was drawn from the antecubital vein in the morning after 12-hour fast for determinations of lipids (HDL-C, LDL-C, and TG), FPG, insulin, HbA1c, and Cr. Blood chemistries were measured at a commercially available laboratory (SRL Inc., Hachioji, Japan). The HOMA-IR index was calculated from the values of FPG $(\mathrm{mg} / \mathrm{dl})$ and insulin $(\mu \mathrm{U} / \mathrm{ml})$ using the following formula [(glucose $\mathrm{x}$ insulin)/405]. eGFR was calculated with the modified isotope dilution mass spectrometry (IDMS)-traceable 4-variable Modification of Diet in Renal Disease (MDRD) Study equation for Japanese. ${ }^{30}$

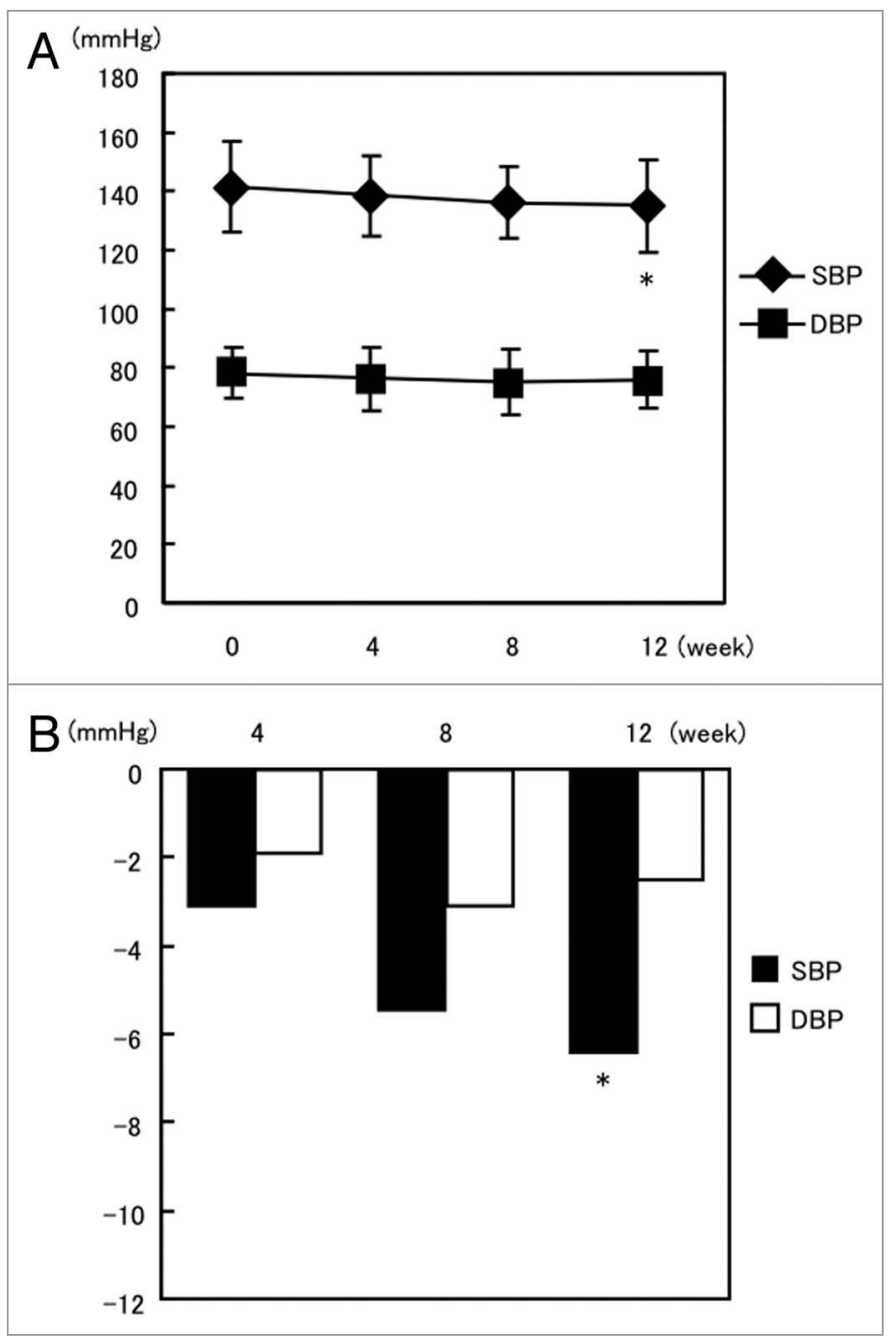

Figure 3. BP levels in patients on switching from candesartan to telmisartan. Replacement of candesartan by telmisartan showed a reduction in both mean systolic blood pressure (SBP) and diastolic blood pressure (DBP) at 4, 8 and 12 weeks. Twenty-five patients (19 males and 6 females) with poorly controlled hypertension were assigned to replace $8 \mathrm{mg}$ candesartan by $40 \mathrm{mg}$ telmisartan. All patients were taking $5 \mathrm{mg}$ amlodipine. (A) SBP and DBP at baseline (0 week) and at 4, 8 and 12 weeks after telmisartan treatment. (B) Mean changes in SBP and DBP from baseline. *, $p<0.05$ compared to the values of baseline.

Statistical methods. Data were expressed as mean \pm standard deviation (SD). To compare the parameter changes between baseline and after the telmisartan treatment, we used the paired t-test. Statistical significance was defined as $\mathrm{p}<0.05$. All statistical analyses were performed with the use of the SAS version 9.2 system (SAS Institute Inc., Cary, NC).

\section{Acknowledgements}

This work was supported in part by Grants of Collaboration with Venture Companies Project from the Ministry of Education, Culture, Sports, Science and Technology, Japan (S.Y). 


\section{References}

1. Black HR. The burden of cardiovascular disease: following the link from hypertension to myocardial infarction and heart failure. Am J Hypertens 2003; 16:4S-6S.

2. Staessen JA, Wang JG, Thijs L. Cardiovascular prevention and blood pressure reduction: a quantitative overview updated until 1 March 2003. J Hypertens 2003; 21:1055-76.

3. Turnbull F. Blood pressure lowering treatment trialists' collaboration. Effects of different blood-pressure-lowering regimens on major cardiovascular events: results of prospectively-designed overviews of randomised trials. Lancet 2003; 362:1527-35.

4. Higaki J, Baba S, Katsuya T, Sato N, Ishikawa K, Mannami T, et al. Deletion allele of angiotensin-converting enzyme gene increases risk of essential hypertension in Japanese men: the Suita Study. Circulation 2000; 101:2060-5.

5. Yamagishi S, Nakamura K, Matsui T. Potential utility of telmisartan, an angiotensin II type 1 receptor blocker with peroxisome proliferator-activated receptor-gamma (PPAR-gamma)-modulating activity for the treatment of cardiometabolic disorders. Curr Mol Med 2007; 7:463-9.

6. Jamerson K, Weber MA, Bakris GL, Dahlöf B, Pitt B, Shi V, et al. Benazepril plus amlodipine or hydrochlorothiazide for hypertension in high-risk patients. $\mathrm{N} \mathrm{Engl} \mathrm{J}$ Med 2008; 359:2417-28.

7. Burnier M, Brunner HR. Angiotensin II receptor antagonists. Lancet 2000; 355:637-45.

8. Brenner BM, Cooper ME, de Zeeuw D, Keane WF, Mitch WE, Parving HH, et al. Effects of losartan on renal and cardiovascular outcomes in patients with type 2 diabetes and nephropathy. N Engl J Med 2001; 345:861-9.

9. Pylypchuk GB. ACE inhibitor- versus angiotensin II blocker-induced cough and angioedema. Ann Pharmacother 1998; 32:1060-6.

10. McDowell SE, Coleman JJ, Ferner RE. Systematic review and mata-analysis of ethnic differences in risks of adverse reactions to drugs used in cardiovascular medicine. BMJ 2006; 332:1177-81.

11. Mancia G, De Backer G, Dominiczak A, Cifkova R, Fagard R, Germano G, et al. 2007 Guidelines for the management of arterial hypertension: The Task Force for the Management of Arterial Hypertension of the European Society of Hypertension (ESH) and of the European Society of Cardiology (ESC). Eur Heart J 2007; 28:1462-536
12. Okano Y, Tamura K, Masuda S, Ozawa M, Tochikubo O, Umemura S. Effects of angiotensin II recepto blockers on the relationships between ambulatory blood pressure and anti-hypertensive effects, autonomic function, and health-related quality of life. Clin Exp Hypertens 2009; 31:680-9.

13. Yamagishi S, Matsui T. Advanced glycation end products (AGEs), oxidative stress and diabetic nephropathy. Oxid Med Cell Longev 2010; 3:101-8.

14. Elahi MM, Kong YX, Matata BM. Oxidative stress as a mediator of cardiovascular disease. Oxid Med Cell Longev 2009; 2:259-69.

15. Higaki J. The ideal combination of anti-hypertensive drugs. Hypertension Res 2009; 32:1059.

16. Chobanian AV, Bakris GL, Black HR, Cushman WC, Green LA, Izzo Jr JL, et al. The seventh report of the joint national committee on prevention, detection, evaluation, and treatment of high blood pressure: the JNC 7 report. JAMA 2003; 289:2560-72.

17. Philipp T, Smith TR, Glazer R, Wernsing M, Yen J, Jin J, et al. Two multicenter, 8-week, randomized, doubleblind, placebo-controlled, parallel-group studies evaluating the efficacy and tolerability of amlodipine and valsartan in combination and as monotherapy in adult patients with mild to moderate essential hypertension. Clin Ther 2007; 29:563-80.

18. Chrysant SG, Melino M, Karki S, Lee J, Heyrman $\mathrm{R}$. The combination of olmesartan medoxomil and amlodipine besylate in controlling high blood pressure: $\mathrm{COACH}$, a randomized, double-blind, placebocontrolled, 8-week factorial efficacy and safety study. Clin Ther 2008; 30:587-604.

19. Williams B, Lacy PS, Thom SM, Cruickshank K, Stanton A, Collier D, et al. Differential impact of blood pressure-lowering drugs on central aortic pressure and clinical outcomes: principal results of the Conduit Artery Function Evaluation (CAFE) study. Circulation 2006; 113:1213-25.

20. Shrestha I, Takahashi T, Nomura E, Ohtsuki T, Ohshita $\mathrm{T}$, Uno $\mathrm{H}$, et al. Association between central systolic blood pressure, white matter lesions in cerebral MRI and carotid atherosclerosis. Hypertension Res 2009; 32:869-74.

21. Kakuta H, Sudoh K, Sasamata M, Yamagishi S. Telmisartan has the strongest binding affinity to angiotensin II type 1 receptor: comparison with other angiotensin II type 1 receptor blockers. Int J Clin Pharmacol Res 2005; 25:414-6.
22. Wienen W, Entzeroth M, van Meel JCA, Stangier J, Busch U, Ebner T, et al. A review on telmisartan: a novel, long-acting angiotensin II-receptor antagonist. Cardiovasc Drugs Rev 2000; 2:127-56.

23. Lacourcière Y, Krzesinski JM, White WB, Davidai G, Schumacher H. Sustained antihypertensive activity of telmisartan compared with valsartan. Blood Press Monit 2004; 9:203-10.

24. Littlejohn T, Mroczek W, Marbury T, VanderMaelen CP, Dubiel RF. A prospective, randomized, open-label trial comparing telmisartan $80 \mathrm{mg}$ with valsartan $80 \mathrm{mg}$ in patients with mild to moderate hypertension using ambulatory blood pressure monitoring. Can J Cardiol 2000; 16:1123-32.

25. Lacourcière $Y$, Lenis J, Orchard R, Lewanczuk R, Houde M, Pesant Y, et al. A comparison of the efficacy and duration of action of the angiotensin II recepto blocker telmisartan to amlodipine. Blood Press Monit 1998; 3:295-302.

26. Nixon RM, Muller E, Lowy A, Falvey H. Valsartan vs. other angiotensin II receptor blocker in the treatment of hypertension: a meta-analytical approach. Int J Clin Pract 2009; 63:766-75.

27. Ogihara T, Kikuchi K, Matsuoka H, Fujita T, Higaki J, Horiuchi M, et al. The Japanese Society of Hypertension Guidelines for the Management of Hypertension (JSH 2009). Chapter 2: Measurement and clinical evaluation of blood pressure. Hypertens Res 2009; 32:11-23.

28. Tahara N, Imaizumi $T$, Takeuchi M, Yamagishi S. Insulin resistance is an independent correlate of high serum levels of advanced glycation end products (AGEs) and low testosterone in non-diabetic men. Oxid Med Cell Longev 2010; 3:262-5.

29. Otsuka T, Kawada T, Ibuki C, Kusama Y. Obesity as an independent influential factor for reduced radial arterial wave reflection in a middle-aged Japanese male population. Hypertens Res 2009; 32:387-91.

30. Matsuo S, Imai E, Horio M, Yasuda Y, Tomita K, Nitta K, et al. Collaborators developing the Japanese equation for estimated GFR. Revised equations for estimated GFR from serum creatinine in Japan. Am J Kidney Dis 2009; 53:982-92. 


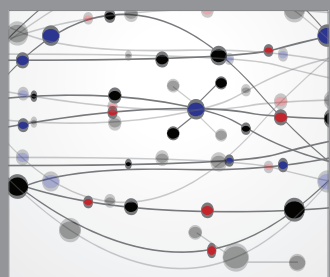

The Scientific World Journal
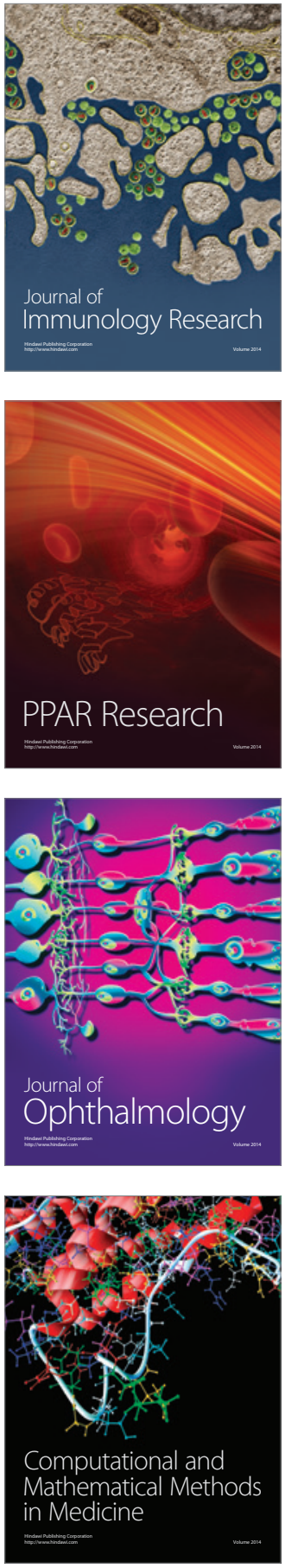

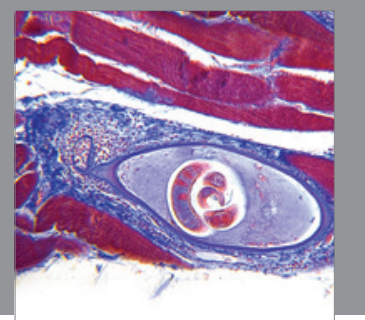

Gastroenterology

Research and Practice
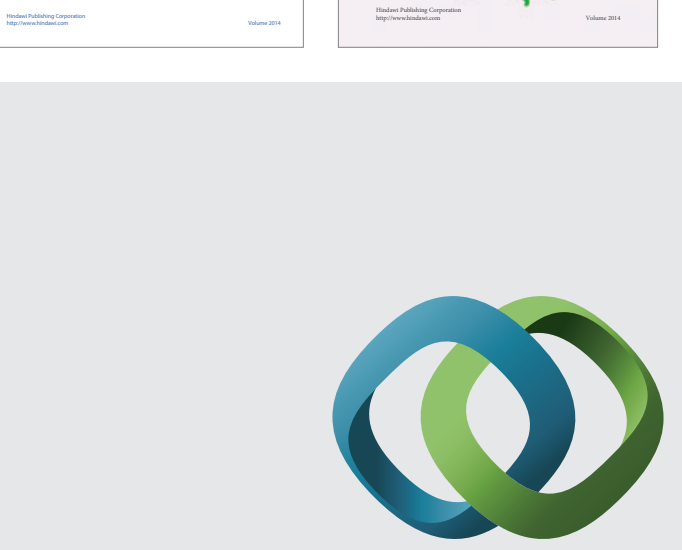

\section{Hindawi}

Submit your manuscripts at

http://www.hindawi.com
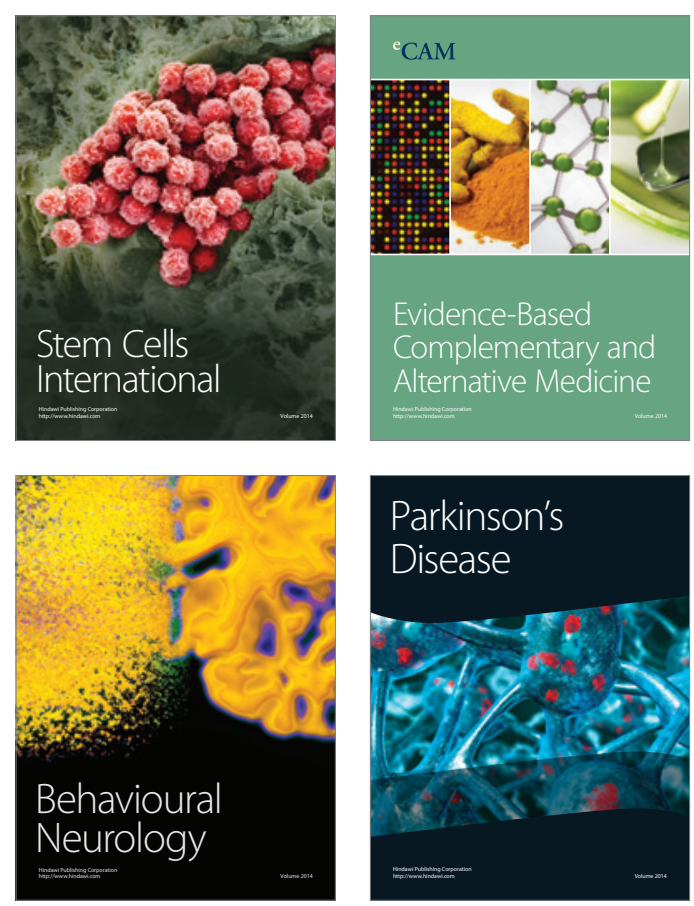

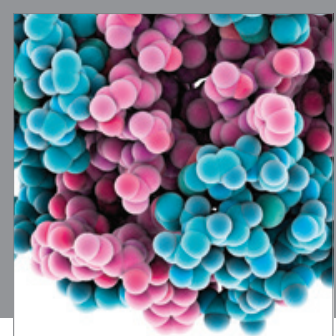

Journal of
Diabetes Research

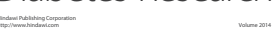

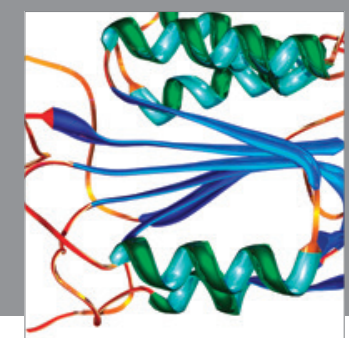

Disease Markers
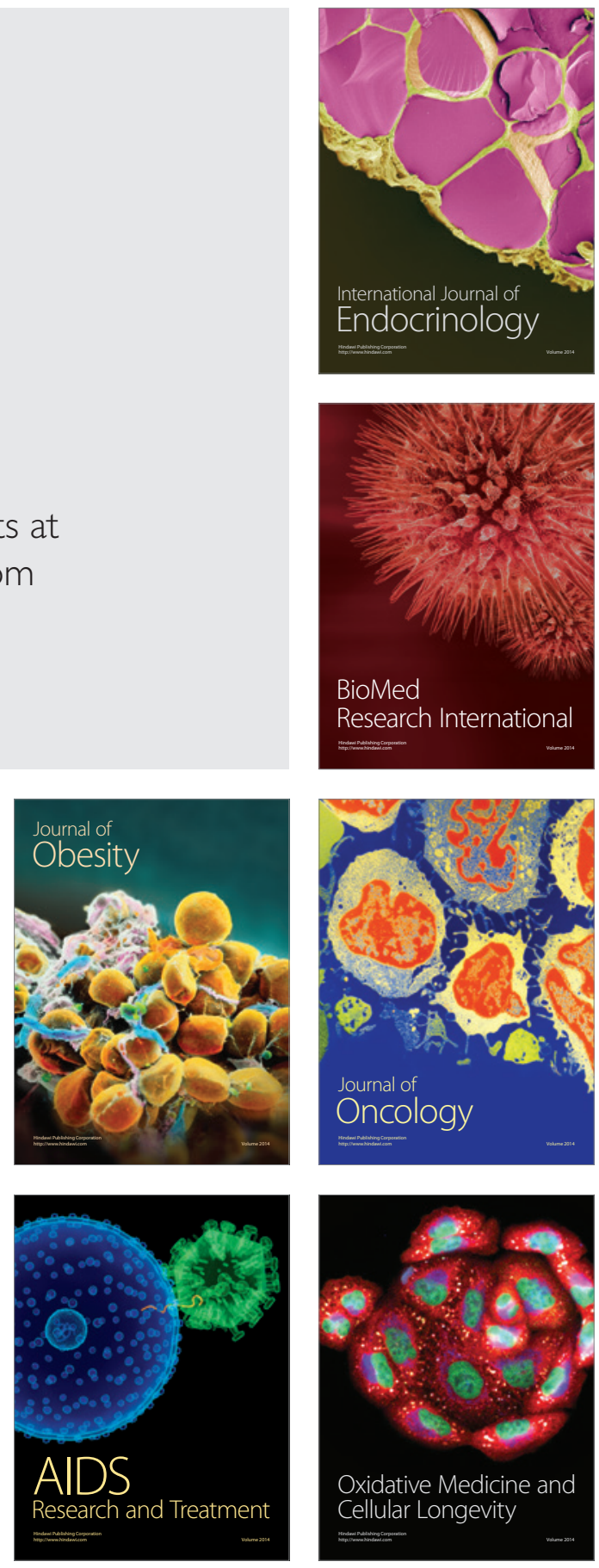